\title{
ERODIBILIDADE DE UM CAMBISSOLO HÚMICO SOB CHUVA NATURAL ${ }^{(1)}$
}

\author{
Jefferson Schick ${ }^{(2)}$, Ildegardis Bertol ${ }^{(3)}$, Neroli Pedro Cogo ${ }^{(4)}$ \& Antonio Paz González ${ }^{(5)}$
}

RESUMO

\begin{abstract}
A estimativa de perdas de solo é fundamental para o planejamento conservacionista. Com essa finalidade, destaca-se no Brasil o uso da Equação Universal de Perdas de Solo (USLE), para cuja utilização há escassez de dados obtidos de acordo com o método-padrão desse modelo. Entre os fatores que compõem a USLE, a erodibilidade do solo (fator K) é de difícil obtenção em razão da necessidade de conduzir experimentos em campo por longo tempo sob chuva natural. Com o objetivo de quantificar a erodibilidade do solo em um Cambissolo Húmico em Lages, SC, utilizando-se do método-padrão da USLE, quantificaram-se a erosividade $\left(\mathrm{EI}_{30}\right)$ das chuvas naturais e as respectivas perdas de solo durante o período de 1993 a 2012 . A erodibilidade foi determinada pelo quociente entre essas variáveis e pela regressão linear simples dessas. $O$ valor de erodibilidade anual estimado pelo quociente e pela regressão linear simples entre as perdas de solo e as erosividades foi respectivamente de 0,0175 e $0,0172 \mathrm{Mg}$ ha h ha-1 $\mathrm{MJ}^{-1} \mathrm{~mm}^{-1}$. A erodibilidade nos períodos de primaveraverão e outono-inverno apresentou pequenas variações em relação à média anual. A erodibilidade mensal variou de $0,0083 \mathrm{Mg}^{\text {ha h ha }} \mathrm{ha}^{-1} \mathrm{MJ}^{-1} \mathrm{~mm}^{-1}$ no mês de dezembro a $0,0241 \mathrm{Mg}$ ha h ha ${ }^{-1} \mathrm{MJ}^{-1} \mathrm{~mm}^{-1}$, no mês de abril. Ao longo do período de tempo avaliado, a erodibilidade anual evidenciou maior incremento nos anos iniciais e menor incremento nos anos finais.
\end{abstract}

Termos de indexação: fator K da USLE, suscetibilidade à erosão, perda de solo.

(1) Parte da Tese de Doutorado do primeiro autor. Recebido para publicação em 20 de março de 2014 e aprovado em $1^{\circ}$ de agosto de 2014.

(2) Professor, Instituto Federal Catarinense, Campus Santa Rosa do Sul. Rua das Rosas, s/n, Vila Nova. CEP $88965-000$ Santa Rosa do Sul (SC). E-mail: jefferson@ifc-sombrio.edu.br

(3) Professor Associado, Universidade do Estado de Santa Catarina. Av. Luiz de Camões, 2090, Bairro Conta Dinheiro. CEP 88520000 Lages (SC). Bolsista do CNPq. E-mail: ildegardis.bertol@udesc.br

(4) Professor, Departamento de Solos, Faculdade de Agronomia, UFRGS. Av. Bento Gonçalves, 7712. Caixa Postal 15.100. CEP 91501-970 Porto Alegre (RS). Bolsista do CNPq. E-mail: neroli@ufrgs.br

(5) Catedrático da Universidade da Coruña, UDC, La Coruña, Espanha. E-mail: tucho@udc.es 


\title{
SUMMARY: ERODIBILITY OF AN INCEPTISOL UNDER NATURAL RAINFALL
}

\begin{abstract}
Estimation of soil loss is critical to conservation planning. To make that estimation, use of the Universal Soil Loss Equation (USLE) is prominent in Brazil. For use of the USLE, there is a shortage of data obtained according to the standard method of this model. Among the factors that compose the USLE, soil erodibility (K factor) is difficult to obtain due to the need to conduct experiments in the field for a long time under natural rainfall. Aiming to quantify soil erodibility in a Humic Inceptisol in Lages, Santa Catarina, Brazil, with the use of the standard method of USLE, we quantified the erosivity $\left(E I_{30}\right)$ of natural rainfall and respective soil loss for the period 1993-2012. Erodibility was determined by the ratio between these variables and by simple linear regression of the same variables. Annual erodibility values, estimated by the ratio and by simple linear regression between soil loss and erosivity, were 0.0175 and $0.0172 \mathrm{Mg} h \mathrm{~h} h \mathrm{ha}^{-1} \mathrm{MJ}^{-1} \mathrm{~mm}^{-1}$, respectively. The erodibility in spring-summer and autumn-winter showed small variations in relation to the annual average. The monthly erodibility ranged from $0.0083 \mathrm{Mg} \mathrm{ha} \mathrm{h} \mathrm{ha-1}^{-1} \mathrm{MJ}^{-1} \mathrm{~mm}^{-1}$ in December to $0.0241 \mathrm{Mg} h \mathrm{~h} \mathrm{~h} \mathrm{~h}^{-1} \mathrm{MJ}^{-1} \mathrm{~mm}^{-1}$ in April. Throughout the time period evaluated, annual erodibility exhibited a greater increase in the initial years and a smaller increase in the final years.
\end{abstract}

Index-terms: USLE K factor, susceptibility to erosion, soil loss.

\section{INTRODUÇÃO}

Alguns solos são mais suscetíveis à erosão do que outros. A maior ou menor vulnerabilidade do solo à erosão é devida as suas propriedades intrínsecas, sendo referida como a erodibilidade do solo (Wischmeier \& Smith, 1978). Wischmeier \& Mannering (1969) observaram que a erodibilidade do solo é uma propriedade complexa que depende tanto da sua capacidade de resistir à dispersão e transporte das partículas pela ação da chuva e enxurrada associada quanto da sua capacidade para infiltrar água.

Wischmeier \& Smith (1965) utilizaram a erodibilidade do solo como um dos fatores da Equação Universal de Perdas de Solo (USLE). Em termos práticos, o índice de erodibilidade (fator K da USLE) significa a perda de solo $\left(\mathrm{Mg} \mathrm{ha}^{-1}\right)$ ocasionada por cada unidade do índice de erosividade (fator R da USLE) das chuvas (MJ mm ha ${ }^{-1} \mathrm{~h}^{-1}$ ), sendo, por isso, expresso em unidades mistas de $\mathrm{Mg}$ ha h ha ${ }^{-1} \mathrm{MJ}^{-1} \mathrm{~mm}^{-1}$. Para condições específicas de chuva, determinado tipo de solo pode ser comparado quantitativamente com outro, podendo, por meio do índice K, ser criada uma escala relativa de valores de erodibilidade (Wischmeier \& Smith, 1978). A obtenção da erodibilidade do solo deve ser feita idealmente em experimentos de campo conduzido por longo tempo, sob chuva natural, segundo Wischmeier \& Smith (1965), cujo método é considerado padrão para esse fim. Wischmeier (1976) estabeleceu, para os solos do leste dos EUA, que o período de avaliação da erosão deve ser de 20 a 22 anos, para efeito de definição do fator erodibilidade.

No Brasil, destacam-se os trabalhos de erodibilidade do solo conduzidos sob chuva natural pelos seguintes autores: Bertoni et al. (1975); Mondardo et al. (1978a); Eltz et al. (1980); Margolis \& Campos Filho (1981); Biscaia et al. (1981); Margolis et al. (1985); Martins Filho \& Silva (1985); Dedecek et al. (1986); Fernandez
Medina \& Oliveira Júnior (1987); Carvalho et al. (1989); Campos Filho et al. (1992); Carvalho et al. (1993); Bertol (1994a); Oliveira Júnior \& Medina (1996); Carvalho et al. (1997); Hernani et al. (1997); Marques et al. (1997a); Silva et al. (1997); Carvalho \& Hernani (2001); Bertol et al. (2002); Albuquerque et al. (2005); Silva et al. (2009); Martins et al. (2011); e Eduardo et al. (2013). Entretanto, nenhum desses trabalhos atendeu o período de avaliação estabelecido por Wischmeier (1976).

Alternativamente ao método-padrão de determinação da erodibilidade do solo, métodos indiretos foram desenvolvidos utilizando características dos solos; entre esses, nos EUA, destacam-se os trabalhos dos seguintes autores: Wischmeier \& Mannering (1969); Wischmeier et al. (1971); Roth et al. (1974); El-Swaify \& Dangler (1977); e Römkens et al. (1977). No Brasil, podem ser citados os seguintes autores: Lombardi Neto \& Bertoni (1975); Denardin (1990); Lima et al. (1990); Roloff \& Denardin (1994); Marques et al. (1997c); Silva et al. (1999); e Sá et al. (2004). Porém, os métodos desenvolvidos nos EUA se evidenciaram inadequados às condições brasileiras (Henklain \& Freire, 1983; Ângulo et al., 1985; Silva et al., 1986; Denardin, 1990; Lima, 1991; Silva et al., 1994; Marques et al., 1997b; Silva et al., 1999), bem como os desenvolvidos no Brasil ainda apresentam limitações ao seu uso (Marques et al., 1997c; Silva et al., 2000; Martins et al., 2011).

Ainda como alternativa ao método-padrão para determinar o fator K da USLE, o uso de simuladores de chuva (Swanson, 1965; Embrapa, 1975) tem possibilitado a condução de experimentos de campo para obtenção de dados num período de tempo relativamente curto. Destacam-se, no Brasil, os trabalhos dos seguintes autores: Mondardo et al. (1978b); Wünsche \& Denardin (1978); Cassol et al. (1980); Denardin \& Wünsche (1980); Resck et al. 
(1981); Dal Conte (1982); Lago \& Margolis (1985); Martins Filho \& Silva (1985); Távora et al. (1985); Rodrigues do Ó (1986); Silva et al. (1986); Martins Filho \& Pereira (1993); Silva et al. (1994); Albuquerque (1997); Bertol et al. (2007); e Eduardo (2012).

O desenvolvimento e, ou, aprimoramento dos métodos indiretos de determinação da erodibilidade do solo e a obtenção da erodibilidade a partir do uso de simuladores de chuva carecem, no Brasil, de valores de referência que tenham sido obtidos de acordo com os pré-requisitos do método-padrão, permitindo assim a validação dos métodos alternativos. Dessa forma, o objetivo deste trabalho foi determinar o fator erodibilidade do solo e sua variação estacional em um Cambissolo Húmico, sob condição de chuva natural, na região de Lages, SC, no período de estudo de erosão compreendido entre 1993 e 2012.

\section{MATERIAL E MÉTODOS}

A pesquisa foi desenvolvida em Lages, SC $\left(27^{\circ} 49^{\prime} \mathrm{S}\right.$ e $50^{\circ} 10^{\prime} \mathrm{W}$ ), no Centro de Ciências Agroveterinárias, da Universidade do Estado de Santa Catarina (CAV/ UDESC), onde a altitude é de $923 \mathrm{~m}$. O clima da região é do tipo $\mathrm{Cfb}$ (temperado, úmido, sem estação seca, com verão fresco), segundo a classificação de Köppen, com temperatura média anual de $15,7^{\circ} \mathrm{C}$ e precipitação pluvial média anual de $1.556 \mathrm{~mm}$ (Wrege et al., 2011). O solo do local do experimento é um Cambissolo Húmico alumínico léptico (Embrapa, 2013), argiloso, com substrato composto de siltitos e argilitos, com declividade média do local igual a $0,102 \mathrm{~m} \mathrm{~m}^{-1}$, descrito em Bertol (1994b).

$\mathrm{O}$ experimento foi conduzido em unidades experimentais, ou parcelas, de 3,5 × 22,1 $\mathrm{m}\left(77,35 \mathrm{~m}^{2}\right)$, em duas repetições. As parcelas foram delimitadas por chapas galvanizadas nas laterais e extremidade superior e por calhas coletoras de enxurrada na sua extremidade inferior, as quais eram conectadas a canos de PVC que conduziam a enxurrada até os pontos de coleta situados $6 \mathrm{~m}$ abaixo dessas. O solo era preparado duas vezes por ano (na primavera-verão e no outonoinverno), com uma aração na profundidade de $0,2 \mathrm{~m}$, utilizando arado de discos, seguidas de duas gradagens na profundidade de $0,15 \mathrm{~m}$, utilizando grade de discos destorroadora. Além disso, a superfície do solo era mantida livre de vegetação e crosta superficial, por meio de capinas e escarificações manuais, efetuadas sempre que necessário.

O experimento foi instalado em outubro de 1988 , sendo, desde então, utilizado no estudo da erosão hídrica em condições de chuva natural. O métodopadrão para obtenção do fator K (Wischmeier \& Smith, 1965) recomenda a utilização dos dados de perda de solo após um período de dois ou mais anos de condução do experimento. Além disso, considerando-se que em
1992 o experimento não foi conduzido adequadamente, utilizaram-se os dados do período entre 1993 e 2012, perfazendo, assim, uma série contínua de 20 anos para este trabalho.

A coleta e a quantificação da erosão foram feitas conforme o método descrito em Cogo (1978). Os dados de perda de solo foram ajustados para a declividade padrão da USLE, ou seja, $0,09 \mathrm{~m} \mathrm{~m}^{-1}$, por meio do fator grau de declive, conforme proposto por Wischmeier \& Smith (1978).

Para determinar o fator de erosividade das chuvas, foram usados pluviogramas diários modelo IH-01-01, com amplitude de registro de $10 \mathrm{~mm}$ de precipitação e de $24 \mathrm{~h}$ de duração, com unidades de $0,2 \mathrm{~mm}$, para o volume, e de $10 \mathrm{~min}$, para o tempo. O critério adotado para definição de chuva erosiva foi o de Wischmeier \& Smith (1958), modificado por Cabeda (1976).

Nos pluviogramas diários, as chuvas erosivas foram cotadas manualmente em segmentos de intensidade uniforme e registradas em planilhas. Posteriormente, utilizou-se o programa Chuveros (Cassol et al., 2008), desenvolvido pelo professor Elemar Antonino Cassol (UFRGS), para calcular a erosividade das chuvas (índice $\mathrm{EI}_{30}$ ), segundo Wischmeier \& Smith (1978). Nesse programa, as unidades foram convertidas para o Sistema Internacional de Unidades, de acordo com Foster et al. (1981).

Durante o período experimental, foram quantificadas as perdas de solo provenientes de 991 chuvas erosivas, as quais originaram 795 eventos individuais de perdas de solo. Desse modo, 163 eventos de perdas de solo foram o resultado de duas ou mais chuvas acumuladas, basicamente em razão da ocorrência dessas chuvas no período noturno, o que impossibilitava sua imediata quantificação. As chuvas erosivas utilizadas neste trabalho representaram aproximadamente $95 \%$ dessas que ocorreram no período entre 1993 e 2012 . Tal fato ocorreu por causa de questões operacionais e essas foram responsáveis pelas pequenas diferenças entre os valores anuais de erosividade apresentados neste trabalho e os constantes na definição do fator $\mathrm{R}$ para a região de Lages, SC (Schick et al., 2014).

O fator de erodibilidade médio anual foi calculado por meio do quociente entre a perda de solo média anual $\left(\mathrm{Mg} \mathrm{ha}^{-1}\right)$ e a erosividade média anual das chuvas (MJ mm ha ${ }^{-1} \mathrm{~h}^{-1}$ ), seguindo o procedimento de Wischmeier \& Smith (1978), bem como por análise de regressão linear simples entre os valores dessas variáveis, seguindo o procedimento de Wischmeier \& Mannering (1969), sendo expresso em $\mathrm{Mg}$ ha h ha ${ }^{-1}$ $\mathrm{MJ}^{-1} \mathrm{~mm}^{-1}$. A erodibilidade do solo também foi determinada para o período de primavera-verão, com 462 dados de perda de solo resultantes de 570 chuvas erosivas, e para o período de outono-inverno, com 333 dados de perda de solo resultantes de 421 chuvas erosivas, ambos por meio do quociente entre os dados das duas variáveis. 
A erodibilidade foi definida ainda para cada um dos meses do ano, por meio do quociente entre a perda de solo mensal e erosividade mensal. A variação mensal da erodibilidade, das perdas de solo, da erosividade das chuvas e da precipitação pluvial total foi obtida pelo quociente entre os valores mensais e o valor anual, sendo os resultados expressos em porcentagem.

Visando observar o efeito do período de avaliação na erodibilidade anual, calculou-se a erodibilidade pelo método proposto por Wischmeier \& Smith (1978). Para isso, inicialmente, consideraram-se apenas os dados do primeiro ano de avaliação; posteriormente, os do primeiro e do segundo ano, depois os do primeiro, segundo e terceiro anos e assim sucessivamente até a utilização de todos os dados da série histórica estudada.

\section{RESULTADOS E DISCUSSÃO}

Observando-se os dados anuais de erosividade, perdas de solo e erodibilidade (Quadro 1), verificou-se que esses variaram amplamente entre os anos estudados, com maior destaque para as perdas de solo e, consequentemente, para a erodibilidade. Essas variações eram em parte esperadas, pois, segundo Wischmeier \& Smith (1978), registros de dados de perda de solo e chuva de curtos períodos de tempo estão sujeitos às variações cíclicas e flutuações aleatórias do clima e às outras variáveis não controladas que se refletem na definição dos fatores da USLE, os quais devem, por isso, serem obtidos em longo prazo. De acordo com Bertol et al. (2002), as variações dos valores do quadro 1 podem ser atribuídas, em parte, às variações de erosividade nos anos considerados, porém, também às variações de teor de água no solo antecedente às chuvas e à não uniformidade de sua distribuição ao longo do período experimental.

Embora os dados de 1989 a 1992 não tenham sido incluídos neste trabalho, os valores de erodibilidade do solo dos três primeiros anos considerados (1993 a 1995) destacam-se como os de menor magnitude (Quadro 1). Entretanto, os dados dos dois últimos anos avaliados (2011 e 2012) distinguem-se como os de maior valor de erodibilidade. Tais resultados estão de acordo com os preceitos de Wischmeier \& Smith (1965), cujos autores recomendam iniciar as avaliações de perdas de solo a partir de um período mínimo de dois anos após a implantação do experimento, na condição-

Quadro 1. Valores médios anuais do fator erosividade - $\mathrm{EI}_{30}$ (fator $\mathrm{R}$ ) das chuvas, da perda de solo e do fator erodibilidade (fator $\mathrm{K}$ ) determinados pelo quociente entre a média das perdas de solo e a média das erosividades das chuvas do Cambissolo Húmico alumínico léptico em Lages, SC, no período de 1993 a 2012

\begin{tabular}{|c|c|c|c|}
\hline Ano & Fator $\mathrm{R}-\mathrm{EI}_{30}$ & Perda de solo ${ }^{(1)}$ & Fator K \\
\hline & MJ mm ha ${ }^{-1} h^{-1}$ & $\mathrm{Mg} \mathrm{ha}^{-1}$ & $\mathrm{Mg}$ ha h ha ${ }^{-1} \mathrm{MJ}^{-1} \mathrm{~mm}^{-1}$ \\
\hline 1993 & 4.975 & 32,2 & 0,0065 \\
\hline 1994 & 5.459 & 40,1 & 0,0074 \\
\hline 1995 & 3.598 & 6,7 & 0,0019 \\
\hline 1996 & 5.189 & 79,5 & 0,0153 \\
\hline 1997 & 7.516 & 101,0 & 0,0134 \\
\hline 1998 & 7.029 & 123,5 & 0,0176 \\
\hline 1999 & 3.467 & 66,1 & 0,0191 \\
\hline 2000 & 6.319 & 115,6 & 0,0183 \\
\hline 2001 & 4.449 & 74,5 & 0,0167 \\
\hline 2002 & 6.141 & 185,4 & 0,0302 \\
\hline 2003 & 3.844 & 51,9 & 0,0135 \\
\hline 2004 & 3.694 & 58,3 & 0,0158 \\
\hline 2005 & 4.238 & 41,9 & 0,0099 \\
\hline 2006 & 3.454 & 50,8 & 0,0147 \\
\hline 2007 & 3.342 & 94,1 & 0,0282 \\
\hline 2008 & 4.538 & 94,7 & 0,0209 \\
\hline 2009 & 5.653 & 129,3 & 0,0229 \\
\hline 2010 & 5.723 & 73,1 & 0,0128 \\
\hline 2011 & 6.002 & 183,3 & 0,0305 \\
\hline 2012 & 3.034 & 103,8 & 0,0342 \\
\hline Média & 4.883 & 85,3 & 0,0175 \\
\hline CV (\%) & 27 & 55 & 49 \\
\hline
\end{tabular}

(1) Média de duas repetições. CV: coeficiente de variação. 
padrão, visando eliminar/diminuir os efeitos de resíduos orgânicos na erodibilidade do solo.

O valor médio anual do fator erodibilidade do solo, obtido por meio do quociente entre a perda de solo média anual e a erosividade média anual (Wischmeier \& Smith, 1978), foi de $0,0175 \mathrm{Mg}$ ha h ha-1 $\mathrm{MJ}^{-1} \mathrm{~mm}^{-1}$ (Quadro 1). De acordo com Foster et al. (1981), essa erodibilidade é classificada como de magnitude moderada. Conceitualmente, a erodibilidade média observada indica que cada unidade de erosividade ocasionou uma perda média anual de solo de 0,0175 $\mathrm{Mg} \mathrm{ha}^{-1}$. Schick et al. (2012), utilizando dados de registros hidrológicos de 22 anos, determinaram o valor de erosividade média anual (Fator $\mathrm{R}$ da USLE) de Lages, SC, igual a $5.057 \mathrm{MJ} \mathrm{mm} \mathrm{ha}^{-1} \mathrm{~h}^{-1}$. Considerando-se o fator $\mathrm{R}$ determinado para o município de Lages e o fator $\mathrm{K}$ obtido para o Cambissolo Húmico neste trabalho, estimou-se perda anual média de solo de $88,5 \mathrm{Mg} \mathrm{ha}^{-1}$, quando o solo estiver descoberto. A tolerância anual de perda de solo, definida por Bertol \& Almeida (2000) para o Cambissolo Húmico, é de 9,2 $\mathrm{Mg} \mathrm{ha}^{-1}$, equivalente, portanto, a $10 \%$ da perda anual estimada para esse tipo de solo.

$\mathrm{O}$ valor do fator $\mathrm{K}$ da USLE, observado neste trabalho (Quadro 1), enquadrou-se na faixa de valores do índice de erodibilidade do solo, medidos e, ou, estimados no Brasil, que é de 0,006 a 0,049 Mg ha h ha'-1 $\mathrm{MJ}^{-1} \mathrm{~mm}^{-1}$, segundo Cogo (1988). O valor de erodibilidade determinado para o Cambissolo Húmico $\left(0,0175 \mathrm{Mg}\right.$ ha h ha-1 $\left.\mathrm{MJ}^{-1} \mathrm{~mm}^{-1}\right)$ é semelhante aos resultados verificados por Silva (1997) em Latossolo Roxo em Chapecó, $\mathrm{SC}\left(0,016 \mathrm{Mg}\right.$ ha h ha $\left.{ }^{-1} \mathrm{MJ}^{-1} \mathrm{~mm}^{-1}\right)$, e por Martins et al. (2011) em Plintossolo Háplico na região dos Tabuleiros Costeiros, ES (0,017 Mg ha h $\left.\mathrm{ha}^{-1} \mathrm{MJ}^{-1} \mathrm{~mm}^{-1}\right)$. Entretanto, difere expressivamente dos resultados observados por Silva et al. (2009) para um Cambissolo Háplico em Lavras, MG (0,0355 $\mathrm{Mg}$ ha h ha $\left.{ }^{-1} \mathrm{MJ}^{-1} \mathrm{~mm}^{-1}\right)$, submetido à erosividade

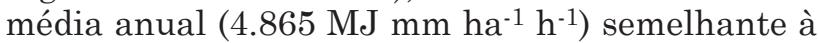
observada neste trabalho (4.883 $\left.\mathrm{MJ} \mathrm{mm} \mathrm{ha}^{-1} \mathrm{~h}^{-1}\right)$ (Quadro 1). Segundo Silva et al. (2009), essa variação de valores do fator Ké devida às variações dos atributos desses solos. El-Swaify \& Dangler (1982) afirmaram não ser recomendado estimar um valor de erodibilidade com base unicamente na classificação do solo. Embora existam diferenças nos períodos de avaliação entre os trabalhos, os resultados observados reforçam as considerações desses autores.

$\mathrm{O}$ valor do fator $\mathrm{K}$ definido por meio de regressão linear simples entre a erosividade das chuvas e suas respectivas perdas de solo, considerando-se todos os eventos individuais de chuva erosiva e de perdas de solo quantificadas para cada uma dessas chuvas, conforme recomendado por Wischmeier \& Mannering (1969), foi de $0,0172 \mathrm{Mg}$ ha h ha-1 $\mathrm{MJ}^{-1} \mathrm{~mm}^{-1}$ (Figura 1a), valor esse semelhante ao obtido pelo método-padrão de cálculo desse fator $\left(0,0175 \mathrm{Mg}\right.$ ha h ha $\left.{ }^{-1} \mathrm{MJ}^{-1} \mathrm{~mm}^{-1}\right)$. Comportamento semelhante a esse foi obtido por Bertol et al. (2007), os quais trabalharam com chuvas simuladas em Nitossolo Háplico. Outras formas de estimar a erodibilidade, recomendadas por Wischmeier \& Mannering (1969), decorreram da realização das seguintes relações, que resultaram nos seguintes valores de fator $\mathrm{K}$ : eventos sem a presença de chuvas acumuladas (Figura $1 b$, fator $K=0,0175$ $\mathrm{Mg}$ ha h ha $\left.\mathrm{h}^{-1} \mathrm{MJ}^{-1} \mathrm{~mm}^{-1}\right)$; eventos com chuvas acumuladas (Figura 1c, fator $\mathrm{K}=0,0166 \mathrm{Mg}$ ha h ha-1 $\mathrm{MJ}^{-1} \mathrm{~mm}^{-1}$ ); valores totais dos períodos de cultivo (Figura 1d, fator $\mathrm{K}=0,0185 \mathrm{Mg}$ ha h ha-1 $\mathrm{MJ}^{-1} \mathrm{~mm}^{-1}$ ); totais dos valores anuais (Figura $1 \mathrm{e}$, fator $\mathrm{K}=0,0176$ $\mathrm{Mg}$ ha h ha-1 $\mathrm{MJ}^{-1} \mathrm{~mm}^{-1}$ ); e valores médios mensais (Figura 1f, fator $\mathrm{K}=0,0177 \mathrm{Mg}$ ha h ha-1 $\mathrm{MJ}^{-1} \mathrm{~mm}^{-1}$ ). Esses valores de fator $\mathrm{K}$ são semelhantes aos obtidos pelo método-padrão. Mesmo assim, como os valores obtidos nessas relações apresentaram baixa confiabilidade, com exceção daquele obtido utilizando as médias mensais (Figura 1e), recomenda-se a utilização do valor do fator $\mathrm{K}$ alcançado pelo quociente entre as perdas de solo e as erosividades das chuvas.

Em relação aos dados estacionais, o período de primavera/verão apresentou, em média, valores de erosividade e de perdas de solo duas vezes maiores do que no período de outono/inverno (Quadro 2), confirmando a tendência observada por Schick (1999) para essas variáveis. Contrariamente ao verificado por Bertol et al. (2002), não foi observada a mesma relação nos valores de erodibilidade, comparando os dois períodos estacionais. Pequenas oscilações da erodibilidade estacional foram observadas em relação ao valor médio anual (Quadro 1), cuja tendência sugere semelhança de erodibilidade do solo nos períodos de primavera/verão e outono/inverno.

No quadro 3, são apresentados os valores médios mensais da erosividade da chuva, do volume das chuvas, das perdas de solo e da erodibilidade do solo, que variaram amplamente ao longo do ano, destacando-se a erosividade e as perdas de solo. A erodibilidade média mensal apresentou, com a precipitação, a menor variação. Ainda assim variou consideravelmente em abril, mês com maior valor, que foi três vezes superior a dezembro, mês com menor valor. Tais resultados corroboram Renard et al. (1997), os quais destacaram a importância do conhecimento da erodibilidade sazonal como forma de reduzir erros nas estimativas de perdas de solo.

Embora a relação entre os valores mensais do fator $\mathrm{R}$ com as perdas de solo seja significativa (Figura 2a), a relação entre os valores do fator $\mathrm{K}$ com a erosividade (Figura $2 \mathrm{~b}$ ), do fator $\mathrm{K}$ com as perdas de solo (Figura 2c) e do fator K com o volume de chuva (Figura $2 \mathrm{~d}$ ) não foi significativa. Isso demonstra que a variação mensal da erodibilidade não é explicada apenas por um dos fatores relacionados, sendo ainda provável a ação de outros fatores não avaliados. Renard et al. (1997) afirmaram que, para as condições dos EUA, a variação sazonal do fator $\mathrm{K}$ deve-se principalmente ao congelamento do solo, à textura e ao conteúdo de água no solo. De acordo com Bertol (1994a), a erodibilidade 

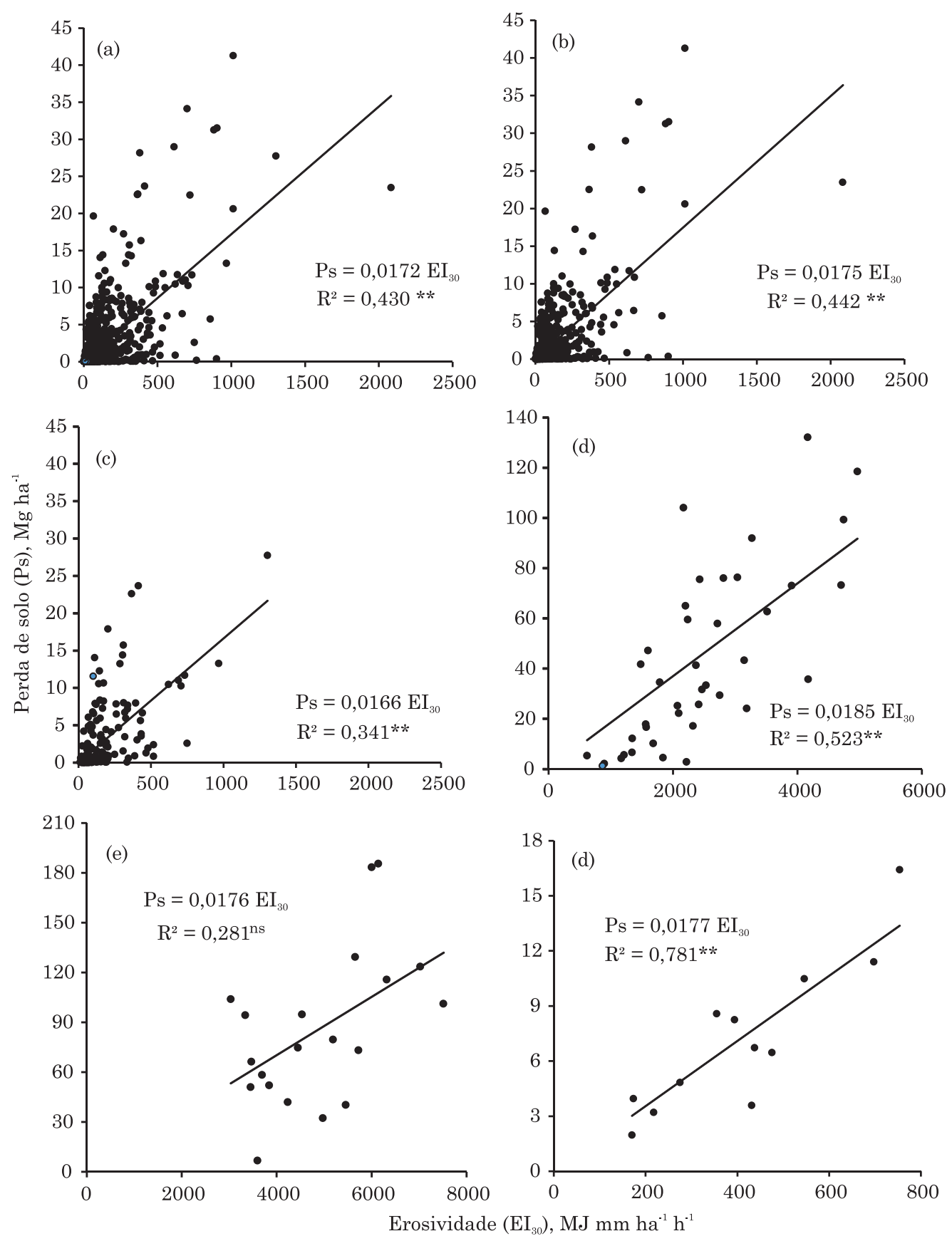

Figura 1. Relação entre perda de solo (Ps) e índice de erosividade $\left(\mathrm{EI}_{30}\right)$ em Cambissolo Húmico entre 1993 e 2012, em Lages, SC, considerando-se: (a) totalidade dos 795 eventos individuais; (b) 632 eventos com chuvas individuais; (c) 163 eventos com chuvas acumuladas; (d) totais dos períodos de cultivo; (e) totais anuais; e (f) médias mensais. **: p<0,01; ns: não significativo.

do solo apresenta grande variabilidade espacial e temporal, explicada pela diversidade climática, a qual influi no potencial erosivo das chuvas e na variabilidade de solo, que tem influência na suscetibilidade à erosão.

Bertol et al. (2002), trabalhando no mesmo solo com dados de nove anos (entre 1989 e 1998), obtiveram valor de erodibilidade igual a $0,0115 \mathrm{Mg}$ ha h ha-1 $\mathrm{MJ}^{-1} \mathrm{~mm}^{-1}$. Este trabalho, apesar de abordar períodos diferentes, resultou em valor de fator K semelhante
(Figura 3) quando considerou os dados do mesmo período de nove anos de pesquisa desses autores. Entretanto, quando estimou os dados do período inteiro de 20 anos, o valor do fator $\mathrm{K}$ é $52 \%$ superior ao verificado por Bertol et al. (2002) naquele período de nove anos. Observou-se, ainda na figura 3, maior incremento no valor de erodibilidade nos anos iniciais e menor incremento nos anos finais, comportamento também verificado por Campos Filho et al. (1992). 
Quadro 2. Valores médios estacionais (primavera/verão e outono/inverno) do fator erosividade - EI $\mathrm{I}_{30}$ (fator $\mathrm{R})$ das chuvas, da perda de solo e do fator erodibilidade (fator $\mathrm{K}$ ) determinados pelo quociente entre a média das perdas de solo e a média das erosividades das chuvas do Cambissolo Húmico alumínico léptico em Lages, SC, no período de 1993 a 2012

\begin{tabular}{|c|c|c|c|c|c|c|}
\hline \multirow[b]{2}{*}{ Ano } & \multicolumn{2}{|c|}{ Fator $\mathrm{R}-\mathrm{EI}_{30}$} & \multicolumn{2}{|c|}{ Perda de solo ${ }^{(1)}$} & \multicolumn{2}{|c|}{ Fator K } \\
\hline & $\begin{array}{c}\text { Primavera/ } \\
\text { verão }\end{array}$ & $\begin{array}{l}\text { Outono/ } \\
\text { inverno }\end{array}$ & $\begin{array}{c}\text { Primavera/ } \\
\text { verão }\end{array}$ & $\begin{array}{l}\text { Outono/ } \\
\text { inverno }\end{array}$ & $\begin{array}{c}\text { Primavera/ } \\
\text { verão }\end{array}$ & $\begin{array}{l}\text { Outono/ } \\
\text { inverno }\end{array}$ \\
\hline & \multicolumn{2}{|c|}{ MJ mm ha ${ }^{-1} \mathrm{~h}^{-1}$} & \multicolumn{2}{|c|}{$-M g h^{-1}-$} & \multicolumn{2}{|c|}{ — Mg ha h ha ${ }^{-1} \mathrm{MJ}^{-1} \mathrm{~mm}^{-1}$} \\
\hline 1993 & 1.654 & 2.239 & 0,49 & 31,04 & 0,0003 & 0,0139 \\
\hline 1994 & 3.316 & 2.092 & 13,91 & 22,83 & 0,0042 & 0,0109 \\
\hline 1995 & 2.482 & 524 & 6,89 & 1,50 & 0,0028 & 0,0029 \\
\hline 1996 & 4.499 & 2.035 & 53,05 & 27,44 & 0,0118 & 0,0135 \\
\hline 1997 & 4.178 & 1.118 & 74,27 & 3,92 & 0,0178 & 0,0035 \\
\hline 1998 & 5.362 & 3.188 & 71,64 & 66,25 & 0,0134 & 0,0208 \\
\hline 1999 & 2.107 & 1.201 & 17,34 & 53,34 & 0,0082 & 0,0444 \\
\hline 2000 & 2.226 & 2.502 & 10,38 & 35,29 & 0,0047 & 0,0141 \\
\hline 2001 & 4.223 & 1.647 & 109,77 & 26,19 & 0,0260 & 0,0159 \\
\hline 2002 & 2.532 & 1.428 & 32,20 & 20,55 & 0,0127 & 0,0144 \\
\hline 2003 & 5.305 & 741 & 175,48 & 14,05 & 0,0331 & 0,0190 \\
\hline 2004 & 2.408 & 731 & 25,26 & 17,85 & 0,0105 & 0,0244 \\
\hline 2005 & 2.426 & 2.184 & 28,42 & 24,09 & 0,0117 & 0,0110 \\
\hline 2006 & 2.943 & 742 & 38,29 & 14,63 & 0,0130 & 0,0197 \\
\hline 2007 & 2.482 & 910 & 48,91 & 25,33 & 0,0197 & 0,0278 \\
\hline 2008 & 3.393 & 1.198 & 82,15 & 28,14 & 0,0242 & 0,0235 \\
\hline 2009 & 2.488 & 2.051 & 56,47 & 49,20 & 0,0227 & 0,0240 \\
\hline 2010 & 3.641 & 2.225 & 57,97 & 36,72 & 0,0159 & 0,0165 \\
\hline 2011 & 5.122 & 2.231 & 105,61 & 87,82 & 0,0206 & 0,0394 \\
\hline 2012 & 2.675 & 692 & 105,50 & 0,92 & 0,0394 & 0,0013 \\
\hline Média & 3.273 & 1.584 & 55,70 & 29,36 & 0,0170 & 0,0185 \\
\hline CV (\%) & 35 & 48 & 79 & 73 & 64 & 60 \\
\hline
\end{tabular}

(1) Média de duas repetições. CV: coeficiente de variação.

Quadro 3. Valores médios mensais do fator erosividade - $\mathrm{EI}_{30}$ (fator $\mathrm{R}$ ) das chuvas, do volume de chuva, da perda de solo e do fator erodibilidade (fator $\mathrm{K}$ ) determinados pelo quociente entre a média das perdas de solo e a média das erosividades das chuvas do Cambissolo Húmico alumínico léptico em Lages, SC, no período de 1993 a 2012

\begin{tabular}{|c|c|c|c|c|}
\hline Mês & Fator R $\left(\mathrm{EI}_{30}\right)$ & Precipitação pluvial & Perda de solo ${ }^{(1)}$ & Fator K \\
\hline & $\mathrm{MJ} m \mathrm{~mm}^{-1} \mathrm{~h}^{-1}$ & $\mathrm{~mm}$ & $\mathrm{Mg} \mathrm{ha}^{-1}$ & $\mathrm{Mg}$ ha h ha ${ }^{-1} \mathrm{MJ}^{-1} \mathrm{~mm}^{-1}$ \\
\hline Janeiro & 697,4 & 138 & 11,39 & 0,0163 \\
\hline Fevereiro & 753,7 & 138 & 16,41 & 0,0218 \\
\hline Março & 393,9 & 89 & 8,24 & 0,0209 \\
\hline Abril & 355,1 & 98 & 8,57 & 0,0241 \\
\hline Maio & 173,7 & 69 & 3,95 & 0,0228 \\
\hline Junho & 170,6 & 82 & 1,96 & 0,0115 \\
\hline Julho & 275,4 & 122 & 4,83 & 0,0175 \\
\hline Agosto & 218,0 & 98 & 3,20 & 0,0147 \\
\hline Setembro & 437,5 & 159 & 6,72 & 0,0154 \\
\hline Outubro & 546,0 & 165 & 10,48 & 0,0192 \\
\hline Novembro & 475,5 & 110 & 6,46 & 0,0136 \\
\hline Dezembro & 431,6 & 93 & 3,58 & 0,0083 \\
\hline Média & 410,7 & 113 & 7,15 & 0,0174 \\
\hline CV (\%) & 46 & 27 & 58 & 28 \\
\hline
\end{tabular}

(1) Média de duas repetições. CV: coeficiente de variação. 


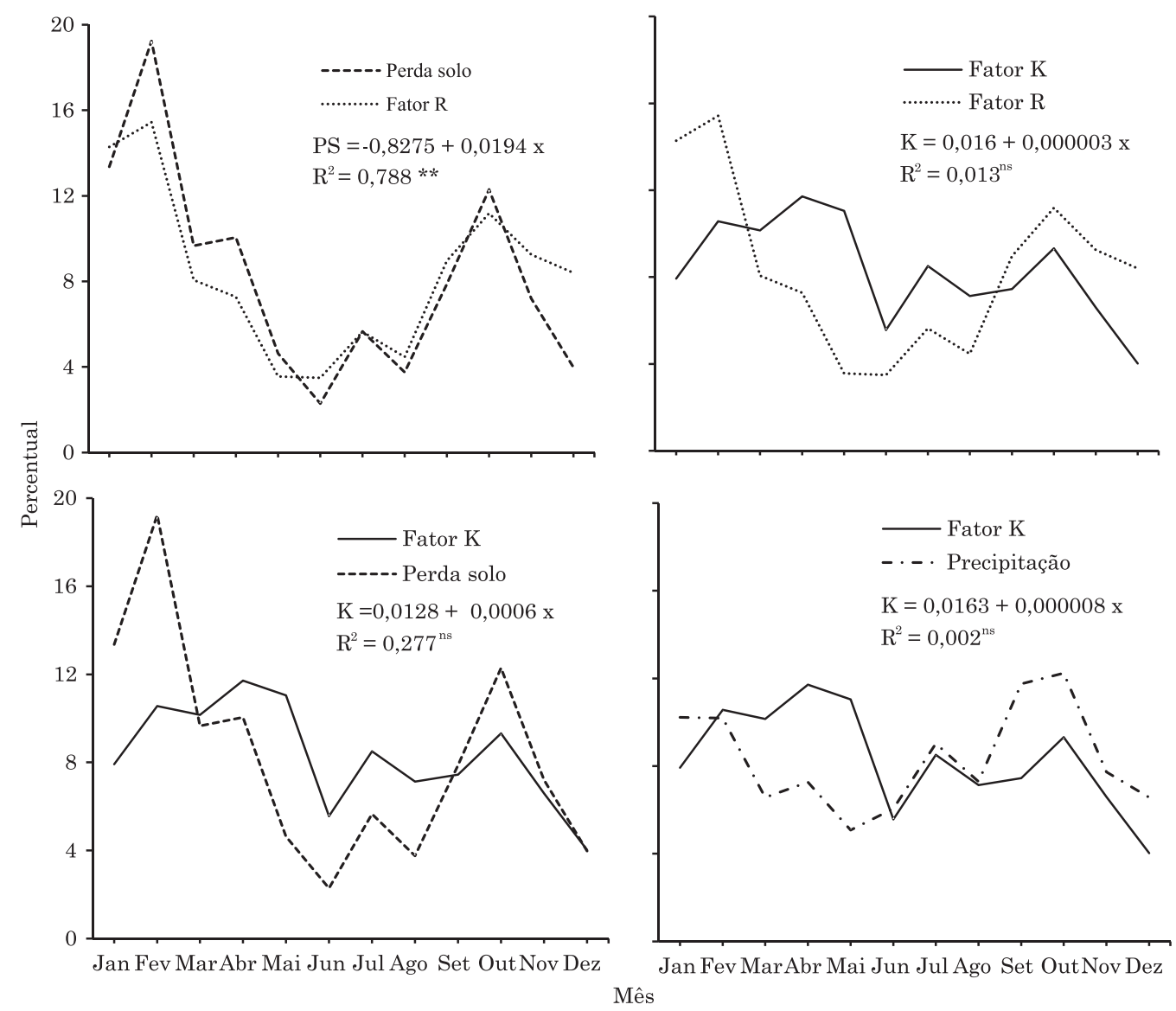

Figura 2. Distribuição mensal da relação entre os valores mensais médios e o valor médio anual, expressos em porcentagem: (a) perda de solo e erosividade das chuvas; (b) erodibilidade do solo e erosividade das chuvas; (c) erodibilidade do solo e perda de solo; (d) erodibilidade do solo e precipitação e relação entre esses fatores, em Lages, SC, entre 1993 e 2012. **: p<0,01; ns: não significativo.

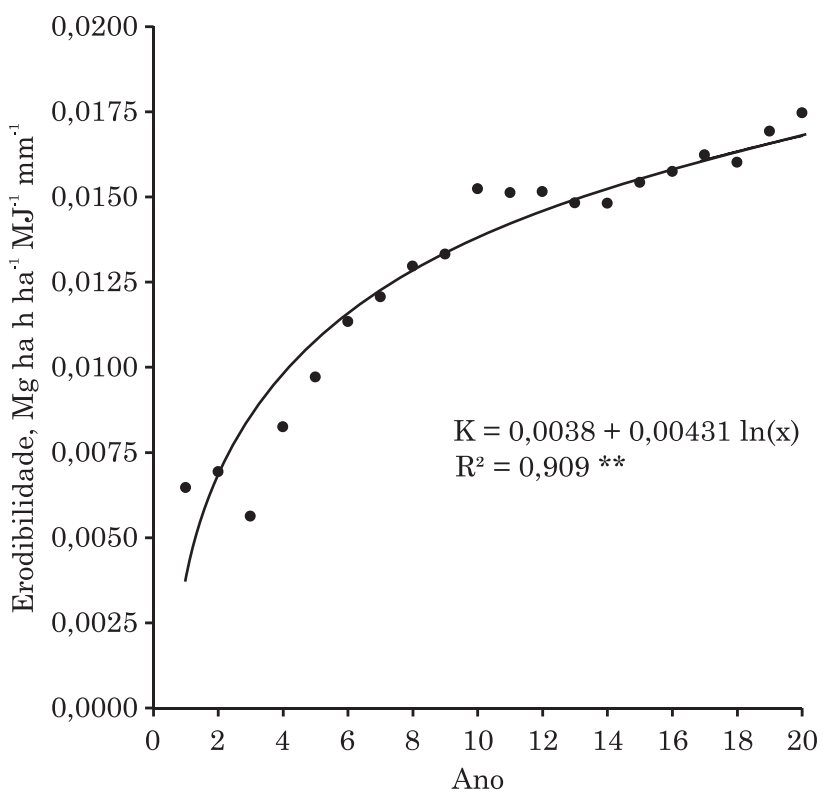

Figura 3. Erodibilidade do solo (K) em função do número de anos observados em Cambissolo Húmico, em Lages, SC. ***: p<0,01.
Esses resultados novamente respaldam o que é pontuado em Wischmeier \& Smith (1965) e em Wischmeier (1976). Esses autores recomendaram que o início da avaliação dos dados de perda de solo deve ser após um período mínimo de dois anos com o solo manejado sob a condição-padrão, definindo, assim, que o fator K deve contemplar 20 anos consecutivos de registro de dados de perda de solo e erosividade das chuvas.

\section{CONCLUSÕES}

1. O fator erodibilidade médio anual do Cambissolo Húmico, determinado pelo quociente entre as perdas médias anuais de solo e as erosividades médias anuais das chuvas, foi de $0,0175 \mathrm{Mg}$ ha h ha-1 $\mathrm{MJ}^{-1} \mathrm{~mm}^{-1}$.

2. $\mathrm{O}$ fator erodibilidade determinado por regressão linear simples foi de $0,0172 \mathrm{Mg}$ ha h ha-1 $\mathrm{MJ}^{-1} \mathrm{~mm}^{-1}$, considerando-se todos os eventos; $0,0175 \mathrm{Mg}$ ha h ha- ${ }^{-1}$ $\mathrm{MJ}^{-1} \mathrm{~mm}^{-1}$, exclusivamente para os eventos de chuvas individuais; $0,0166 \mathrm{Mg}$ ha h ha ${ }^{-1} \mathrm{MJ}^{-1} \mathrm{~mm}^{-1}$, para os eventos de chuvas acumuladas; $0,0185 \mathrm{Mg}$ ha h ha-1 
$\mathrm{MJ}^{-1} \mathrm{~mm}^{-1}$, para os totais dos períodos de cultivo; $0,0176 \mathrm{Mg}$ ha h ha-1 $\mathrm{MJ}^{-1} \mathrm{~mm}^{-1}$, para os totais anuais; e $0,0177 \mathrm{Mg}$ ha h ha-1 $\mathrm{MJ}^{-1} \mathrm{~mm}^{-1}$, considerando as médias mensais.

3. O fator K foi de $0,0170 \mathrm{Mg}$ ha h ha ${ }^{-1} \mathrm{MJ}^{-1} \mathrm{~mm}^{-1}$, utilizando somente os dados de primavera/verão, enquanto com os de outono/inverno, o fator $\mathrm{K}$ resultante foi de $0,0185 \mathrm{Mg}$ ha $\mathrm{h} \mathrm{ha}^{-1} \mathrm{MJ}^{-1} \mathrm{~mm}^{-1}$.

4. A erodibilidade média mensal variou nos meses do ano entre $0,0083 \mathrm{Mg}$ ha h ha-1 $\mathrm{MJ}^{-1} \mathrm{~mm}^{-1}$, em dezembro, e $0,0241 \mathrm{Mg}$ ha h ha ${ }^{-1} \mathrm{MJ}^{-1} \mathrm{~mm}^{-1}$, em abril.

\section{AGRADECIMENTOS}

Ao CNPq, por parte dos recursos financeiros e pela bolsa PQ do segundo autor. À FINEP e FAPESC, por parte dos recursos financeiros. Ao Professor David José Miquelluti (UDESC/CAV), pelo auxílio na análise estatística dos dados. Aos bolsistas IC de Uso e Conservação do Solo, pela ajuda na condução do experimento em campo.

\section{LITERATURA CITADA}

ALBUQUERQUE, A.W. Determinação de fatores para a equação universal de perdas de solo nas condições de Sumé-PB. Piracicaba, Escola Superior de Agricultura Luiz de Queiroz, 1997. 100p. (Tese de Doutorado)

ALBUQUERQUE, A.W.; FILHO, G.M.; SANTOS, J.R.; COSTA, J.P.V. \& SOUZA, J.L. Determinação de fatores da equação universal de perda de solo em Sumé, PB. R. Bras. Eng. Agríc. Amb., 9:153-160, 2005.

ÂNGULO, R.J.; ROLOFF, G. \& SOUZA, M.L.P. Aplicabilidade do nomograma de Wischmeier et al. (1971) para determinação da erodibilidade de solos brasileiros. R. Ci. Agrár., 7:145-153, 1985.

BERTOL, I. Erodibilidade de um Cambissolo Húmico distrófico determinada sob chuva natural: Primeira aproximação. R. Bras. Ci. Solo, 18:335-338, 1994a.

BERTOL, I. Erosão hídrica em Cambissolo Húmico distrófico sob diferentes preparos do solo e rotação de cultura. R. Bras. Ci. Solo, 18:267-271, 1994b.

BERTOL, I. \& ALMEIDA, J.A. Tolerância de perda de solo por erosão para os principais solos do Estado de Santa Catarina. R. Bras. Ci. Solo, 24:657-668, 2000.

BERTOL, I.; SCHICK, J.; BATISTELA, O.; LEITE, D. \& AMARAL, A.J. Erodibilidade de um Cambissolo Húmico alumínico léptico, determinada sob chuva natural entre 1989 e 1998 em Lages (SC). R. Bras. Ci. Solo, 26:465-471, 2002.

BERTOL, I.; LEITE, D.; ENGEL, F.L.; COGO, N.P. \& GONZÁLEZ, A.P. Erodibilidade de um Nitossolo Háplico alumínico determinada em condições de campo. R. Bras. Ci. Solo, 31:541-549, 2007.
BERTONI, J.; LOMBARDI NETO, F. \& BENATTI Jr., R. Equação de perdas de solo. Campinas, Instituto Agronômico de Campinas, 1975. 25p. (Boletim Técnico, 21)

BISCAIA, R.C.M.; RUFINO, R.L. \& HENKLAIN, J.C. Cálculo de erodibilidade (fator K) de dois solos do Estado do Paraná. R. Bras. Ci. Solo, 5:183-186, 1981.

CABEDA, M.S.V. Computations of storms EI values. West Lafayette, Purdue University, 1976. 6p. (Não Publicado)

CAMPOS FILHO, O.R.; SILVA, I.F.; ANDRADE, A.P. \& LEPRUN, J.C. Erosividade da chuva e erodibilidade do solo no agreste de Pernambuco. Pesq. Agropec. Bras., 27:1363-1370, 1992.

CARVALHO, M.P. \& HERNANI, L.C. Parâmetros de erosividade da chuva e da enxurrada correlacionados com perdas de solo e erodibilidade de um Latossolo Roxo de Dourados (MS). R. Bras. Ci. Solo, 25:137-146, 2001.

CARVALHO, M.P.; CATANEO, A. \& LOMBARDI NETO, F. Índices de erosividade da chuva e enxurrada correlacionados com as perdas de solo e determinação da erodibilidade de um Latossolo Roxo distrófico de Campinas (SP). R. Bras. Ci. Solo, 17:445-450, 1993.

CARVALHO, M.P.; CATANEO, A. \& LOMBARDI NETO, F. Parâmetros de erosividade da chuva e da enxurrada correlacionados com as perdas de solo e determinação da erodibilidade de um Podzólico Vermelho-Amarelo de Pindorama. R. Bras. Ci. Solo, 21:279-286, 1997.

CARVALHO, M.P.; LOMBARDI NETO, F.; VASQUES FILHO, J. \& CATANEO, A. Índices de erosividade da chuva correlacionados com as perdas de solo de um Podzólico Vermelho eutrófico textura argilosa/muito argilosa de Mococa (SP): Primeira aproximação do fator erodibilidade do solo. R. Bras. Ci. Solo, 13:237-242, 1989.

CASSOL, E.A.; ELTZ, F.L.F. \& GUERRA, M. Erodibilidade do solo "São Jerônimo" (Laterítico Bruno Avermelhado distrófico) determinada com simulador de chuvas. In: ENCONTRO NACIONAL DE PESQUISA SOBRE CONSERVAÇÃO DO SOLO, 3., Recife, 1980. Anais... Recife, SBCS-UFRPE-IPA-Sudene, 1980. p.203-208.

CASSOL, E.A.; ELTZ, F.L.F.; MARTINS, D.; LEMOS, A.M.; LIMA, V.S. \& BUENO, A.C. Erosividade, padrões hidrológicos, período de retorno e probabilidade de ocorrência das chuvas em São Borja, RS. R. Bras. Ci. Solo, 32:1239-1251, 2008.

COGO, N.P. Conceitos e princípios científicos envolvidos no manejo de solo para fins de controle da erosão hídrica. In: CONGRESSO BRASILEIRO DE CIÊNCIA DO SOLO, 21., Campinas, 1988. Anais... Campinas, Sociedade Brasileira de Ciência do Solo, 1988. p.251-262.

COGO, N.P. Uma contribuição à metodologia de estudo das perdas de erosão em condições de chuva natural. I. Sugestões gerais, medição dos volumes, amostragem e quantificação de solo e água da enxurrada (1 ${ }^{\text {a }}$ aproximação). In: ENCONTRO NACIONAL DE PESQUISA SOBRE CONSERVAÇÃO DO SOLO, 2., Passo Fundo, 1978. Anais... Passo Fundo, Empresa Brasileira de Pesquisa Agropecuária, 1978. p.75-98. 
DAL CONTE, F.M. Índice de erodibilidade de um solo Podzólico Vermelho-Amarelo, determinado sob chuva simulada. Santa Maria, Universidade Federal de Santa Maria, 1982. 67p. (Dissertação de Mestrado)

DEDECEK, R.A.; RESCK, D.V.S. \& FREITAS JUNIOR, E. Perdas de solo, água e nutrientes por erosão em Latossolo Vermelho-Escuro dos cerrados em diferentes cultivos sob chuva natural. R. Bras. Ci. Solo, 10:265-272, 1986.

DENARDIN, J.E. Erodibilidade de solo estimada por meio de parâmetros físicos e químicos. Piracicaba, Escola Superior de Agricultura Luiz de Queiroz, 1990. 81p. (Tese de Doutorado)

DENARDIN, J.E. \& WÜNSCHE, W.A. Erodibilidade de um Latossolo Vermelho-Escuro. In: ENCONTRO NACIONAL DE PESQUISA SOBRE CONSERVAÇÃO DO SOLO, 3., Recife, 1980. Anais... Recife, Universidade Federal Rural de Pernambuco, 1980. p.219.

EDUARDO, E.N. Determinação da erodibilidade e do fator cobertura e manejo do solo sob condições de chuva natural e simulada. Seropédica, Universidade Federal do Rio de Janeiro, 2012. 56p. (Dissertação de Mestrado)

EDUARDO, E.N.; CARVALHO, D.F.; MACHADO, R.L.; SOARES, P.F.C. \& ALMEIDA, W.S. Erodibilidade, fatores cobertura e manejo e práticas conservacionistas em Argissolo Vermelho Amarelo, sob condições de chuva natural. R. Bras. Ci. Solo, 37:796-803, 2013.

EL-SWAIFY, S.A. \& DANGLER, E.W. Erodibilities of selected tropical soils in relation to structural and hydrologic parameters. In: NATIONAL CONFERENCE ON SOIL EROSION, 30., West Lafayette, 1976. Proceedings... Ankeny, Soil and Water Conservation Society, 1977.

EL-SWAIFY, S.A. \& DANGLER, E.W. Rainfall erosion in the tropics: a state of art. In: KREBS, D.M., ed. Determinants of soil loss tolerance. Madison, American Society of Agronomy, 1982.

ELTZ, F.L.F.; SCOPEL, I.; CASSOL, E.A. \& GUERRA, M. Perdas por erosão em diferentes manejos de solo e coberturas vegetais em solo Laterítico Bruno Avermelhado distrófico (São Jerônimo) sob chuva natural; resultados dos primeiros cinco anos. In: ENCONTRO NACIONAL DE PESQUISA SOBRE CONSERVAÇÃO DO SOLO, 3., Recife, 1980. Anais... Recife, SBCS-UFRPEIPA-Sudene, 1980. p.305-307.

EMPRESA BRASILEIRA DE PESQUISA AGROPECUÁRIA EMBRAPA. Recomendações gerais do encontro sobre uso do simulador de chuva em pesquisa de conservação do solo no Brasil. In: ENCONTRO NACIONAL SOBRE PESQUISA DE EROSÃO COM SIMULADORES DE CHUVA, 1975, Londrina. Resumos... Londrina, Embrapa, 1975. p.107-120.

EMPRESA BRASILEIRA DE PESQUISA AGROPECUÁRIA EMBRAPA. Sistema brasileiro de classificação de solos. 3.ed. Brasília, Embrapa Solos, 2013. 353p.

FERNANDEZ MEDINA, B. \& OLIVEIRA JÚNIOR, R.C. A aplicabilidade de alguns índices erosivos em Latossolo Amarelo de Manaus (AM). R. Bras. Ci. Solo, 11:67-70, 1987.
FOSTER, G.R.; McCOOL, D.K.; RENARD, K.G. \& MOLDENHAUER, W.C. Conversion of the universal soil loss equation to SI metric units. J. Soil Water Conserv., 36:355-359, 1981.

HENKLAIN, J.C. \& FREIRE, O. Avaliação do método monográfico para determinação da erodibilidade de Latossolos do Estado do Paraná. R. Bras. Ci. Solo, 7:191195, 1983.

HERNANI, L.C.; SALTON, J.C.; FABRÍCIO, A.C.; DEDECEK, R. \& ALVES JÚNIOR, M. Perdas por erosão e rendimentos de soja e de trigo em diferentes sistemas de preparo de um Latossolo Roxo de Dourados (MS). R. Bras. Ci. Solo, 21:667-676, 1997.

LAGO, J.C. \& MARGOLIS, E. Erodibilidade de um solo Podzólico Vermelho-Amarelo eutrófico, pelos métodos da chuva natural e simulador de chuvas, no sertão de Pernambuco. Agros, 20:25-36, 1985.

LIMA, P.M.P. Índices de erodibilidade diretos e indiretos para dois Latossolos do município de Lavras - Minas Gerais. Ci. Prat., 15:186-193, 1991.

LIMA, J.M.; CURI, N.; RESENDE, M. \& SANTANA, D.P. Dispersão do material de solo em água para avaliação indireta da erodibilidade de Latossolos. R. Bras. Ci. Solo, 14:85-90, 1990.

LOMBARDI NETO, F. \& BERTONI, J. Erodibilidade de solos paulistas. Campinas, Instituto Agronômico, 1975. 12p. (Boletim Técnico, 27)

MARGOLIS, E. \& CAMPOS FILHO, O.R. Determinação dos fatores da equação universal de perdas de solo num Podzólico Amarelo de Glória de Goitá. In: ENCONTRO NACIONAL DE PESQUISA SOBRE CONSERVAÇÃO DO SOLO, 3., Recife, 1980. Anais... Recife, Universidade Federal Rural de Pernambuco, 1981. p.239-250.

MARGOLIS, E.; SILVA, A.B. \& JACQUES, F.O. Determinação dos fatores da equação universal de perda de solo para as condições de Caruaru (PE). R. Bras. Ci. Solo, 9:165-169, 1985.

MARQUES, J.J.G.S.M.; ALVARENGA, R.C.; CURI, N.; SANTANA, D.P. \& SILVA, M.L.N. Índices de erosividade da chuva, perdas de solo e fator erodibilidade para dois solos da região dos cerrados primeira aproximação. R. Bras. Ci. Solo, 21:427-434, 1997a.

MARQUES, J.J.G.M.; CURI, N.; FERREIRA, M.M.; LIMA, J.M.; SILVA, M.L.N. \& CAROLINO SÁ, M.A. Adequação de métodos indiretos para estimativa da erodibilidade de solos com horizonte B textural no Brasil. R. Bras. Ci. Solo, 21:447-456, 1997b.

MARQUES, J.J.G.M.; CURI, N.; LIMA, J.M.; FERREIRA, M.M.; SILVA, M.L.N. \& FERREIRA, D.F. Estimativa da erodibilidade a partir de atributos de solos com horizonte B textural no Brasil. R. Bras. Ci. Solo, 21:457$465,1997 \mathrm{c}$.

MARTINS FILHO, E.M.V. \& PEREIRA, V.P. Influência da compactação do solo nas perdas por erosão e na sua erodibilidade. Ci. Agron., 8:39-45, 1993. 
MARTINS FILHO, E.M.V. \& SILVA, J.R.C. Comparação de métodos de avaliação da erodibilidade de um Latossolo Vermelho distrófico. R. Bras. Ci. Solo, 9:175-177, 1985.

MARTINS, S.G.; AVANZI, J.C.; SILVA, M.L.N.; CURI, N. \& FONSECA, S. Erodibilidade do solo nos tabuleiros costeiros. Pesq. Agropec. Trop., 41:322-327, 2011.

MONDARDO, A.; FARIA, G.S.; CASTRO FILHO, C.; VIEIRA, M.J.; HENKLAIN, J.C. \& RUFINO, R.L. Índices de erodibilidade de alguns solos do Estado do Paraná. In: ENCONTRO NACIONAL DE PESQUISA SOBRE CONSERVAÇÃO DO SOLO, 2., Passo Fundo, 1978. Anais... Passo Fundo, Embrapa, 1978a. p.199-201.

MONDARDO, A.; JUCKSCH, I.; VIEIRA, M.J.; FARIAS, G.S.; HENKLAIN, J.C. \& RUFINO, R.L. Erodibilidade do Latossolo Roxo distrófico com $8 \%$ de declive, usando simulador de chuva. Londrina, IAPAR, 1978b.

OLIVEIRA JÚNIOR, R.C. \& MEDINA, B.F. Comparação entre a erodibilidade medida diretamente e a estimada pelo método nomográfico em Latossolo Amarelo textura muito argilosa. Belém, Embrapa-CPATU, 1996. 11p. (Boletim de Pesquisa, 164)

RENARD, K.G.; FOSTER, G.R.; WEESIES, G.A.; McCOOL, D.K. \& YODER, D.C. Predicting soil erosion by water: a guide to conservation planning with the revised universal soil loss equation (RUSLE). Washington, USDA, 1997. (Agricultural Handbook, 8)

RESCK, D.V.S.; FIGUEIREDO, M.S.; FERNANDES, B.; RESENDE, M. \& SILVA, T.C.A. Erodibilidade de um Podzólico Vermelho-Amarelo Câmbico distrófico fase terraço, localizado na Zona da Mata (MG), determinada com simulador de chuva. R. Bras. Ci. Solo, 5:7-14, 1981.

RODRIGUES DO Ó, N.C. Erodibilidade das principais classes de solo do Estado da Paraíba determinada por chuva simulada e método nomográfico. Areia, Universidade Federal da Paraíba, 1986. 29p. (Dissertação de Mestrado)

ROLOFF, G. \& DENARDIN, J.E. Estimativa simplificada da erodibilidade do solo. In: REUNIÃO BRASILEIRA DE MANEJO E CONSERVAÇÃO DO SOLO E DA ÁGUA, 10., Florianópolis, 1994. Resumos... Florianópolis, SBCS, 1994. p.150-151.

RÖMKENS, M.J.M.; ROTH, C.B. \& NELSON, D.W. Erodibility of select clay subsoils in relation to physical and chemical properties. Soil Sci. Soc. Am. J., 41:954-960, 1977.

ROTH, C.B.; NELSON, D.W. \& RÖMKENS, M.J.M. Prediction of subsoil erodibility using chemical, mineralogical and physical parameters. Washington, United States Environmental Protection Agency, 1974. 111p.

SÁ, M.A.C.; CURI, N.; LIMA, J.M.; MARQUES, J.J.G.S.M. \& MASSAROTO, J.A. Estimativa da erodibilidade pela desagregação por ultra-som e atributos de solos com horizonte B textural. Pesq. Agropec. Bras., 39:691-699, 2004.

SCHICK, J. Erosão hídrica em Cambissolo Húmico álico submetido a diferentes sistemas de preparo e cultivo do solo. Lages, Universidade do Estado de Santa Catarina, 1999. 114p. (Dissertação de Mestrado)
SCHICK, J.; BERTOL, I.; COGO, N.P \& GONZÁLEZ, A.P. Erosividade das chuvas de Lages, Santa Catarina. R. Bras. Ci. Solo, 38:1890-1905, 2014.

SCHICK, J.; BERTOL, I.; BARBOSA, F.T.; GONZALEZ, A.P.; VÁZQUEZ, E.V.; WERNER, R.S.; RAMOS, J.C.; FLORES, M.C.; BANDEIRA, D.H.; CASTELANI, H. \& TANAKA, M.S. Erosividade das chuvas e sua distribuição entre 1989 e 2010 no município de Lages (SC). In: REUNIÃO BRASILEIRA DE MANEJO E CONSERVAÇÃO DO SOLO E DA ÁGUA, 19., Lages, 2012. Anais... Lages, 2012. CD-ROM

SILVA, M.L.N. Erosividade da chuva e proposição de modelos para estimar a erodibilidade de Latossolos brasileiros. Lavras, Universidade Federal de Lavras, 1997. 154p. (Tese de Doutorado)

SILVA, A.M.; SILVA, M.L.N.; CURI, N.; AVANZI, J.C. \& FERREIRA, M.M. Erosividade da chuva e erodibilidade de Cambissolo e Latossolo na região de Lavras, Sul de Minas Gerais. R. Bras. Ci. Solo, 33:1811-1820, 2009.

SILVA, I.F.; ANDRADE, A.P. \& CAMPOS FILHO, O.R. Erodibilidade de seis solos do semi-árido paraibano obtida com chuva simulada e método nomográfico. R. Bras. Ci. Solo, 10:283-287, 1986 .

SILVA, M.L.N.; CURI, N.; LIMA, J.M. \& FERREIRA, M.M. Avaliação de métodos indiretos de determinação da erodibilidade de Latossolos Brasileiros. Pesq. Agropec. Bras., 35:1207-1220, 2000.

SILVA, M.L.N.; CURI, N.; FERREIRA, M.M.; LIMA, J.M. \& FERREIRA, D.F. Proposição de modelos para estimativa da erodibilidade de Latossolos Brasileiros. Pesq. Agropec. Bras., 34:2287-2298, 1999.

SILVA, M.L.N.; CURI, N.; OLIVEIRA, M.S.; FERREIRA, M.M. \& LOMBARDI NETO, F. Comparação entre métodos diretos e indiretos para determinação da erodibilidade em Latossolos sob cerrado. Pesq. Agropec. Bras., 29:17511761, 1994.

SILVA, M.L.N.; FREITAS, P.L.; BLANCANEAUX, P.; CURI, N. \& LIMA, J.M. Relação entre parâmetros da chuva e perdas de solo e determinação da erodibilidade de um Latossolo Vermelho-Escuro em Goiânia (GO). R. Bras. Ci. Solo, 21:131-137, 1997.

SWANSON, N.P. A rotating-boom rainfal simulator. Trans. ASAE, 8:71-72, 1965.

TÁVORA, M.R.P.; SILVA, J.R.C. \& MOREIRA, E.G.S. Erodibilidade de dois solos da região de Ibiapaba, Estado do Ceará. R. Bras. Ci. Solo, 9:59-62, 1985.

WISCHMEIER, W.H. Use and misuse of the universal soil loss equation. J. Soil Water Conserv., 31:5-9, 1976.

WISCHMEIER, W.H. \& MANNERING, J.V. Relation of soil properties to its erodibility. Proc. Soil Sci. Soc. Am., 33:131137, 1969.

WISCHMEIER, W.H. \& SMITH, D.D. Rainfall energy and its relationship to soil loss. Trans. Am. Geophys. Union, 39:285-291, 1958. 
WISCHMEIER, W.H. \& SMITH, D.D. Predicting rainfall erosion losses from cropland east of the Rocky Mountains: Guide for selection of practices for soil and water conservation. Washington, USDA, 1965. 47p. (Agriculture handbook, 282)

WISCHMEIER, W.H. \& SMITH, D.D. Predicting rainfall erosion losses: A guide to conservation planning. Washington, USDA, 1978. 58p. (Agriculture Handbook, 537)

WISCHMEIER, W.H.; JOHNSON, C.B. \& CROSS, B.V. Soil erodibility nomograph for farmland and construction sites. J. Soil Water Conserv., 26:189-193, 1971.
WREGE, M.S.; STEINMETZ, S.; REISSER JÚNIOR, C. \& ALMEIDA, I.R., eds. Atlas climático da Região Sul do Brasil: Estados do Paraná, Santa Catarina e Rio Grande do Sul. Pelotas, Embrapa Clima Temperado; Colombo, Embrapa Florestas, 2011. v.1, 332p.

WÜNSCHE, W.A. \& DENARDIN, J.E. Erodibilidade de Latossolo Vermelho-Escuro álico (Unidade de Mapeamento Passo Fundo) - $1^{a}$ aproximação. In: ENCONTRO NACIONAL DE PESQUISA SOBRE CONSERVAÇÃO DO SOLO, 2., Passo Fundo, 1978. Anais... Passo Fundo, CNPT, 1978. p.209-214. 